\title{
Análise numérica da variação dimensional em blocos cerâmicos estruturais durante o
}

\section{processo de secagem}

Numerical analysis of the dimensional variation in structural ceramic blocks during the drying

process

Análisis numérico de la variación dimensional en bloques cerámicos estructurales durante el

proceso de secado

Recebido: 02/05/2021 | Revisado: 10/05/2021 | Aceito: 13/05/2021 | Publicado: 31/05/2021

Stephane Katherine Barbosa Moura da Silva
ORCID: https://orcid.org/0000-0002-7187-419X
Universidade Federal de Campina Grande, Brasil
E-mail: katherine.b.moura@ @mail.com
Carlos José de Araújo
ORCID: https://orcid.org/0000-0001-8939-0946
Universidade Federal de Campina Grande, Brasil
E-mail: carlos.araujo@ufcg.edu.br
Antonio Gilson Barbosa de Lima
ORCID: https://orcid.org/0000-0003-1691-1872
Universidade Federal de Campina Grande, Brasil
E-mail: antonio.gilson@ufcg.edu.br

\begin{abstract}
Resumo
Possuindo produtos com um custo de produção relativamente baixo, a indústria cerâmica é um segmento com participação fundamental na economia nacional. Todavia, trata-se de indústrias que, em sua maioria possuem processos de fabricação ultrapassados, sem controle de qualidade adequado, e que geram um elevado desperdício de recursos e baixa qualidade da peça final. Sendo uma das etapas do processo de fabricação de um material cerâmico, a secagem é definida como o processo de redução do teor de umidade de um sólido em função do fornecimento de energia ao mesmo. Trata-se de um processo que envolve fenômenos complexos de transferência de calor e massa, assim como variações dimensionais, e que, quando realizado de forma incorreta, acarreta danos estruturais ao produto, os quais são os principais responsáveis pelo descarte de peças na indústria cerâmica. Logo, é de suma importância descrever detalhadamente o processo de secagem, fornecendo informações necessárias para que o processo ocorra de forma adequada. Destarte, a presente pesquisa teve como objetivo, através da modelagem matemática e simulação numérica, analisar a variação dimensional de um bloco cerâmico estrutural durante o processo de secagem, onde modelos matemáticos para volume e área superficial do produto foram ajustados via software Statistica ${ }^{\circledR}$ aos dados experimentais obtidos na literatura, em diversas condições experimentais. Resultados referentes às variações das áreas superficiais externa e interna e volume foram expostos e analisados. Pode-se concluir que o modelo matemático escolhido ajustou-se adequadamente aos dados experimentais coletados, com coeficiente de determinação superior à 0.9; e que, apesar de sofrer reduções dimensionais, o bloco cerâmico estudado manteve sua geometria inicial sem apresentar deformações.
\end{abstract}

Palavras-chave: Blocos cerâmicos; Modelagem matemática; Secagem; Teor de umidade; Variação dimensional.

\begin{abstract}
Having products with a relatively low production cost, the ceramic industry is a segment with a fundamental participation in the national economy. However, these are industries that, for the most part, have obsolete manufacturing processes, without adequate quality control, and which generate a high waste of resources and low quality of the final product. As one of the steps in the manufacturing process of a ceramic material, drying is defined as the process of reducing the moisture content of a solid by supplying energy. It's a process that involves complex phenomena of heat and mass transfer, as well as dimensional variations, and which, when done incorrectly, causes structural damage to the product, which are the main responsible for the disposal of parts in the ceramic industry. Therefore, it's extremely important to describe the drying process in detail, providing the necessary information for the process to occur properly. Thus, this research aimed, through mathematical modeling and numerical simulation, to analyze the dimensional variation of a structural ceramic block during the drying process, where mathematical models for volume and surface area of the product were adjusted using Statistica ${ }^{\circledR}$ software to the data experimental data obtained in the literature, under different experimental conditions. Results related to the variations of the external and internal surface areas and volume were exposed and analyzed. It can be concluded that the mathematical model
\end{abstract}


chosen was adequately adjusted to the experimental data collected, with a coefficient of determination that was higher than 0.9; and that, despite undergoing dimensional reductions, the studied ceramic block maintained its initial geometry without showing deformations.

Keywords: Ceramic blocks; Dimensional variation; Drying; Mathematical modeling; Moisture content.

\section{Resumen}

Por tener productos con un costo de producción relativamente bajo, la industria cerámica es un segmento con una participación fundamental en la economía nacional. Sin embargo, se trata de industrias que, en su mayor parte, tienen procesos de fabricación desactualizados, sin un adecuado control de calidad, y que generan un alto desperdicio de recursos y baja calidad del producto final. Como uno de los pasos en el proceso de fabricación de un material cerámico, el secado se define como el proceso de reducción del contenido de humedad de un sólido de acuerdo con el suministro de energía al mismo. Es un proceso que involucra fenómenos complejos de transferencia de calor y masa, así como variaciones dimensionales, y que, cuando se realizan de manera incorrecta, provocan daños estructurales al producto, que es el principal responsable del retiro de piezas en la industria cerámica. Por tanto, es de suma importancia describir el proceso de secado en detalle, proporcionando la información necesaria para que el proceso se lleve a cabo correctamente. Así, esta investigación tuvo como objetivo, a través de la modelización matemática y la simulación numérica, analizar la variación dimensional de un bloque cerámico estructural durante el proceso de secado, donde se ajustaron modelos matemáticos de volumen y superficie del producto mediante el software Statistica ${ }^{\circledR}$ a datos experimentales obtenidos en la literatura, bajo diferentes condiciones experimentales. Se expusieron y analizaron los resultados relacionados con variaciones en superficies y volumen externo e interno. Se puede concluir que el modelo matemático elegido se ajustó adecuadamente a los datos experimentales recolectados, con un coeficiente de determinación mayor a 0.9 ; y que, a pesar de sufrir reducciones dimensionales, el bloque cerámico estudiado mantuvo su geometría inicial sin presentar deformaciones.

Palabras clave: Bloques de cerámica; Contenido de humedad; Modelado matemático; Secado; Variación dimensional.

\section{Introdução}

A história da cerâmica é concomitante a história das civilizações. Sendo utilizados há milênios, os materiais cerâmicos são empregados em atividades que vão desde as mais básicas, como o bloco estrutural utilizado na construção civil, até as mais avançadas. Possuindo como principal componente a argila, a cerâmica tem suas propriedades finais definidas de acordo com as características deste componente, em especial, sua plasticidade, que permite a cerâmica ser conformada em distintas formas quando hidratada (Barros, 2021). De acordo com Platão, a conformação cerâmica foi uma das primeiras atividades manuais desenvolvidas pelo homem, uma vez que, em busca de uma melhor qualidade de vida, passou a utilizar o barro, mesmo que seco, na fabricação de peças, como jarros, tigelas e vasos, e na construção de casas, muros e torres. Logo, para muitos, a cerâmica é considerada a mais antiga das indústrias.

Despontando como segmento industrial em solo brasileiro a partir do século XIX, a cerâmica ocupa um lugar de destaque na economia brasileira. Trata-se de um setor diversificado que se divide em inúmeros segmentos, dando ênfase ao da cerâmica vermelha, classe a qual pertencem os blocos cerâmicos estruturais (Bellingieri, 2005; Motta, Zanardo, \& Cabral Júnior, 2001). Os blocos cerâmicos estruturais são componentes imprescindíveis na indústria civil, e em especial, na alvenaria estrutural (Alexandre, 2017). Segundo Martinez (2017) e Santos (2019), os blocos cerâmicos são produtos utilizados como materiais de construção desde a antiguidade devido a sua satisfatória resistência mecânica, durabilidade e conforto térmico. Ademais, são produtos que apresentam facilidade e baixo custo de produção, cujo processo de fabricação, assim como os dos demais materiais cerâmicos, abrange etapas como a exploração de jazidas, beneficiamento, homogeneização, conformação, secagem e queima.

A secagem pode ser definida como o processo de remoção higroscópica da água contida em um material (Zaccaron, 2020). Ou em outras palavras, define-se como um processo termodinâmico no qual ocorre a redução do teor de umidade de um sólido em função do fornecimento de energia ao mesmo. Trata-se de um processo que envolve fenômenos complexos de transferência de calor e massa simultânea, ocasionando uma mudança no estado da água existente no interior do sólido, onde a mesma passa do estado líquido para o estado vapor, sendo em seguida evaporada para o ambiente. O objetivo da secagem é a 
redução do teor de umidade dos produtos. Durante essa etapa, devido a perda de umidade, ocorre o fenômeno de encolhimento (ou retração) que, além de alterar a cinética de secagem do material, também altera suas dimensões. Como, durante a secagem, o teor de umidade tem uma influência significativa na perda de umidade e retração volumétrica, se este processo for realizado de forma incorreta, provocará danos estruturais ao produto comprometendo assim sua qualidade e desempenho, causando um grande descarte de peças (Ibrahim, 1997; Nascimento et al., 2005; Braga et al., 2016; Brito, 2016; Nascimento et al., 2019; E. Lima et al., 2020).

Estima-se que com o cenário de produção atual, cerca de 30\% da produção diária das indústrias cerâmicas é descartada devido a problemas em alguma das etapas do processo de fabricação (Prado \& Bressiani, 2013). Afere-se que, dentre todas essas etapas, a secagem é a maior responsável por esses descartes. Deste modo, conhecer e descrever detalhadamente o mecanismo de transferência de umidade e calor em sólidos cerâmicos torna-se de suma importância, uma vez que fornece informações necessárias para que o processo ocorra de forma adequada, evitando descartes e produzindo peças de ótima qualidade. Conquanto, apesar da relevância, estudos acerca da secagem de materiais cerâmicos são conduzidos em sua maioria, à nível experimental, limitando-se a condições operacionais específicas, sendo poucos os estudos que envolvem modelagem matemática e simulação numérica (Araújo et al., 2020; Lima et al., 2020).

A modelagem matemática é uma área de conhecimento que estuda a simulação de sistemas reais com o intuito de prever o seu comportamento, ou seja, trata-se de uma área de conhecimento que tenta descrever matematicamente um fenômeno físico (Lima, 2017; Nascimento et al., 2020). Como a secagem é uma das etapas do processo de fabricação dos materiais cerâmicos que mais provoca problemas na peça, descrever o comportamento do teor de umidade em um sólido em função do tempo, através de modelos matemáticos, torna-se de grande relevância, principalmente ao nível industrial, uma vez que permite um melhor aproveitamento desse processo. Para estudar teoricamente a secagem, vários modelos matemáticos têm sido propostos a fim de descrever a taxa de perda de umidade em produtos cerâmicos. Por tratar-se de um processo bastante complexo, há a necessidade da utilização de modelos matemáticos que se assemelhem, numericamente, com o processo real. Logo, a simulação matemática do processo de secagem viabiliza uma otimização desse processo, permitindo que este seja realizado de forma econômica e em um tempo menor (Faustino, 2016).

Ainda que haja na literatura diversas soluções analíticas e numéricas que descrevam o processo de secagem, muitos dos estudos reportados ainda estão associados à modelos matemáticos que necessitam de melhoramentos, dependendo do tipo de material estudado. Em geral, os modelos matemáticos propostos para predizer o processo de secagem relacionam o teor de umidade do sólido cerâmico em função do tempo de processo. No entanto, raros são aqueles modelos que descrevem o comportamento das variações dimensionais do produto em função do tempo de processo, o que gera uma necessidade para tais pesquisas.

Destarte, a presente pesquisa tem como objetivo estudar as variações dimensionais de blocos cerâmicos estruturais durante o processo de secagem, por meio de uma modelagem matemática agrupada, regressões estatísticas não-lineares e simulação numérica. A ideia é ajustar acadêmicos, industriais e engenheiros na tomada de decisão relacionadas a otimização do processo de secagem em termos de energia e qualidade do produto.

\section{Metodologia}

\section{Problema Físico e a Geometria}

O presente estudo traz uma abordagem numérica acerca da variação dimensional sofrida por um bloco cerâmico estrutural durante o seu processo de secagem convectiva. A Figura 1 esquematiza o bloco cerâmico estrutural com geometria paralelepipédica estudado nesta pesquisa. A Figura 2 exibe a vista frontal (2D) do bloco cerâmico, dando ênfase aos seus furos paralelepipédicos e circulares, e suas respectivas dimensões. 
Figura 1. Geometria em 3D do bloco cerâmico estrutural.

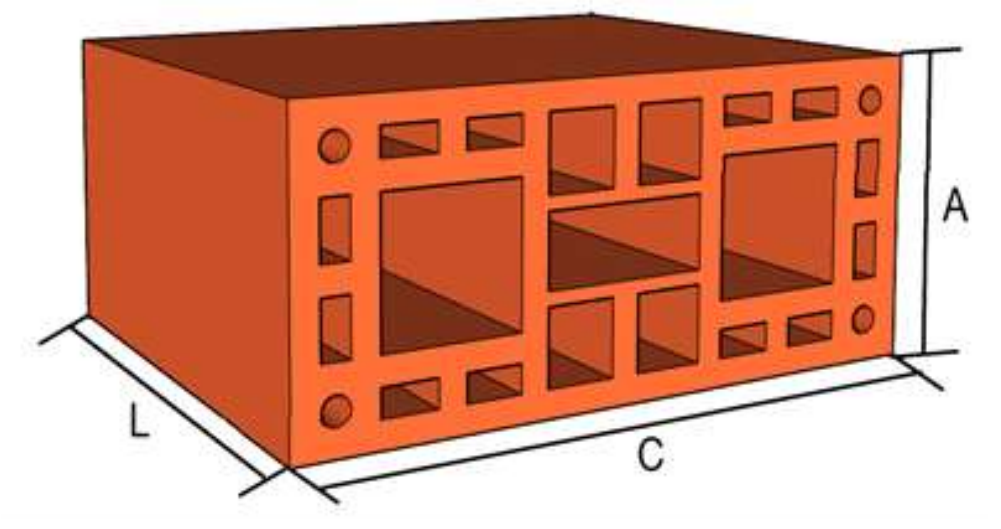

Fonte: Dados da Pesquisa.

Figura 2. Geometria da face frontal do bloco cerâmico.

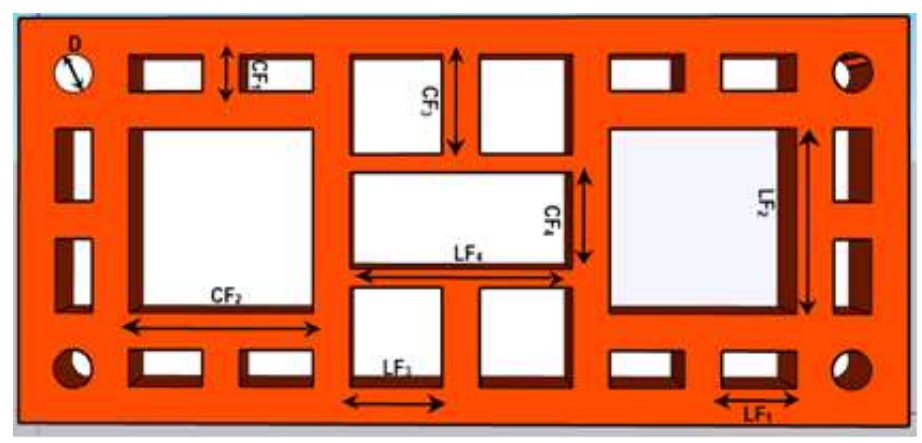

Fonte: Dados da Pesquisa.

Para descrever numericamente a variação dimensional de um bloco cerâmico durante o seu processo de secagem (transferência de calor e massa), algumas hipóteses foram consideradas: a) O bloco estrutural é isotrópico e constituído de matéria sólida (argila) e água; b) A água, em seu estado líquido, migra do interior do sólido evaporando em sua superfície; e c) As dimensões do bloco variam com o tempo durante todo o processo.

\section{Experimentos de Secagem do Bloco Cerâmico Estrutural}

Nesta pesquisa, para analisar o comportamento das áreas superficiais (externa e interna) e do volume do bloco cerâmico, e determinar os seus parâmetros geométricos no decorrer do processo de secagem, foram utilizados diversos dados dimensionais reportados por Silva (2018), em seu estudo experimental relacionado ao processo de secagem desse produto em distintas condições operacionais.

Em sua investigação, Silva (2018) cita que, antes de submeter os blocos cerâmicos ao processo de secagem em estufa, foram realizadas medições de seu comprimento, largura e altura, bem como largura, altura e diâmetro dos seus furos paralelepipédicos e circulares. Além disso, também foram realizadas aferições acerca da massa e temperatura do bloco cerâmico, e da umidade relativa, temperatura e velocidade do ar de secagem. Na Tabela 1 encontram-se dispostos, para as condições da investigação experimental, os dados iniciais do bloco e do ar de secagem, já na Tabela 2, apresentam-se os dados referentes à geometria inicial do bloco. Após essas medições, os blocos cerâmicos foram submetidos à secagem. 
Tabela 1. Parâmetros experimentais para o ar de secagem e o bloco cerâmico no início do processo de secagem.

\begin{tabular}{c|c|c|c|c|c}
\hline \multirow{2}{*}{ Teste } & \multicolumn{3}{|c|}{ Ar } & \multicolumn{2}{c}{ Bloco Cerâmico } \\
\cline { 2 - 6 } & $\mathbf{T}\left({ }^{\circ} \mathbf{C}\right)$ & $\mathbf{U R}(\boldsymbol{\%})$ & $\mathbf{v}(\mathbf{m} / \mathbf{s})$ & $\mathbf{M}_{\mathbf{0}}$ (kg/kg;b.s.) & $\mathbf{T}_{\mathbf{0}}\left({ }^{\circ} \mathbf{C}\right)$ \\
\hline 1 & 50 & 18,39 & 1,0 & 0,1723191 & 31,5 \\
\hline 2 & 60 & 12,27 & 1,0 & 0,173163 & 32,0 \\
\hline 3 & 70 & 7,72 & 1,0 & 0,170186 & 29,8 \\
\hline 4 & 80 & 4,99 & 1,0 & 0,172723 & 30,5 \\
\hline 5 & 90 & 3,56 & 1,0 & 0,167900 & 27,6 \\
\hline 6 & 100 & 2,34 & 1,0 & 0,169366 & 27,5 \\
\hline
\end{tabular}

Fonte: Silva (2018).

Tabela 2. Dimensões iniciais do bloco cerâmico.

Dimensões iniciais do bloco cerâmico para cada tempo de secagem

\begin{tabular}{c|c|c|c|c|c|c|c|c|c|c|c|c}
\hline $\begin{array}{c}\mathbf{T} \\
\left({ }^{\mathbf{C}}\right)\end{array}$ & $\begin{array}{c}\mathbf{A} \\
(\mathbf{m})\end{array}$ & $\begin{array}{c}\mathbf{L} \\
(\mathbf{m})\end{array}$ & $\begin{array}{c}\mathbf{C} \\
(\mathbf{m})\end{array}$ & $\begin{array}{c}\mathbf{D} \\
(\mathbf{m})\end{array}$ & $\begin{array}{c}\mathbf{C F} \\
(\mathbf{m})\end{array}$ & $\begin{array}{c}\mathbf{L F} \\
(\mathbf{m})\end{array}$ & $\begin{array}{c}\mathbf{C F}_{2} \\
(\mathbf{m})\end{array}$ & $\begin{array}{c}\mathbf{L F} \\
(\mathbf{m})\end{array}$ & $\begin{array}{c}\mathbf{C F}_{3} \\
(\mathbf{m})\end{array}$ & $\begin{array}{c}\mathbf{L F}_{3} \\
(\mathbf{m})\end{array}$ & $\begin{array}{c}\mathbf{C F}_{4} \\
(\mathbf{m})\end{array}$ & $\begin{array}{c}\mathbf{L F}_{4} \\
(\mathbf{m})\end{array}$ \\
\hline 50 & 0,143 & 0,199 & 0,303 & 0,014 & 0,015 & 0,033 & 0,073 & 0,075 & 0,038 & 0,024 & 0,031 & 0,062 \\
\hline 60 & 0,140 & 0,200 & 0,302 & 0,015 & 0,015 & 0,033 & 0,072 & 0,078 & 0,037 & 0,028 & 0,030 & 0,064 \\
\hline 70 & 0,142 & 0,200 & 0,300 & 0,015 & 0,033 & 0,015 & 0,074 & 0075 & 0,036 & 0,026 & 0,031 & 0,062 \\
\hline 80 & 0,144 & 0,200 & 0,300 & 0,015 & 0,015 & 0,033 & 0,074 & 0,074 & 0,035 & 0,026 & 0,031 & 0,063 \\
\hline 90 & 0,143 & 0,199 & 0,300 & 0,015 & 0,015 & 0,034 & 0,073 & 0,075 & 0,036 & 0,026 & 0,030 & 0,063 \\
\hline 100 & 0,142 & 0,201 & 0,301 & 0,014 & 0,015 & 0,031 & 0,073 & 0,075 & 0,036 & 0,026 & 0,030 & 0,063 \\
\hline
\end{tabular}

Fonte: Silva (2018).

$\mathrm{Na}$ etapa de secagem em estufa, foram realizados 6 testes com temperaturas distintas $\left(50^{\circ} \mathrm{C}, 60^{\circ} \mathrm{C}, 70^{\circ} \mathrm{C}, 80^{\circ} \mathrm{C}, 90^{\circ} \mathrm{C}\right.$ e $100^{\circ} \mathrm{C}$ ) as quais foram mantidas fixas durante cada teste, com o auxílio de controladores de temperatura. Durante os testes, em intervalos pré-definidos, o bloco era retirado da estufa, possibilitando a medição da temperatura, massa e dimensões do mesmo. Essas medições foram realizadas em intervalos iniciais de 5, 10 e 30 minutos, cada qual com 6 repetições para cada uma das temperaturas fixadas, e em seguida, com intervalos de 60 minutos até que a massa do bloco atingisse um valor constante. Após atingir uma massa constante, o bloco foi submetido a duas secagens de 24 horas, sendo a primeira realizada na mesma temperatura de secagem, visando à obtenção da massa de equilíbrio do bloco, enquanto a segunda etapa foi realizada na temperatura fixa de $100{ }^{\circ} \mathrm{C}$, tendo o objetivo de se obter a massa seca da peça. Na Tabela 3 são reportados os dados obtidos nos experimentos. 
Tabela 3. Parâmetros experimentais do bloco cerâmico após a secagem.

\begin{tabular}{c|c|c|c}
\hline \multicolumn{4}{c}{ Parâmetros experimentais obtidos após a secagem } \\
\hline Teste & $\mathbf{M}_{\mathbf{e}}(\mathbf{k g} / \mathbf{k g} ; \mathbf{b . s .})$ & $\mathbf{T}_{\mathbf{e}}\left({ }^{\circ} \mathbf{C}\right)$ & $\mathbf{t}(\mathbf{m i n})$ \\
\hline 1 & 0,002685 & 50,5 & 1170 \\
\hline 2 & 0,001834 & 58,0 & 1050 \\
\hline 3 & 0,001189 & 64,7 & 990 \\
\hline 4 & 0,000826 & 68,6 & 930 \\
\hline 5 & 0,000511 & 76,2 & 930 \\
\hline 6 & 0,000054 & 95,1 & 750 \\
\hline
\end{tabular}

Fonte: Silva (2018).

\section{Parâmetros Dimensionais do Bloco Cerâmico}

As variações do volume e áreas superficiais interna e externa do bloco cerâmico em função do tempo de secagem para cada temperatura de teste $\left(\mathrm{de} \mathrm{T}=50^{\circ} \mathrm{C}\right.$ à $\left.\mathrm{T}=100^{\circ} \mathrm{C}\right)$ foram determinadas através do software Microsoft Excel ${ }^{\circledR}$ com o auxílio dos dados dimensionais obtidos por Silva (2018) e dos cálculos auxiliares dispostos a seguir.

\section{a) Volume do Bloco Cerâmico}

$\mathrm{O}$ volume total do bloco $\left(\mathrm{V}_{\mathrm{t}}\right)$ para cada tempo de secagem foi calculado a partir de suas dimensões geométricas $(\mathrm{C}=$ largura; $\mathrm{L}=$ comprimento; $\mathrm{A}$ = altura) e das respectivas dimensões de seus furos, com o auxílio das seguintes equações:

$$
\begin{aligned}
& V_{f}=\left[12\left(L C_{1} L_{1}\right)+2\left(L_{C F} L_{2}\right)+4\left(L_{C} F_{3} L_{3}\right)+4\left(\pi r^{2} L\right)+\left(L_{C F} L_{4} F_{4}\right)\right] \\
& V_{t}=(A C L)-V_{f}
\end{aligned}
$$

sendo $\mathrm{V}_{\mathrm{f}} \mathrm{O}$ volume dos furos e $\mathrm{V}_{\mathrm{t}} \mathrm{o}$ volume total do bloco cerâmico, respectivamente.

\section{b) Áreas Superficiais Externa e Interna do Bloco Cerâmico}

Assim como o volume total, as áreas superficiais externa $\left(S_{1}\right)$ e interna $\left(S_{2}\right)$ do bloco cerâmico em cada tempo de secagem foram calculados a partir das dimensões da geometria do bloco $(\mathrm{L}=$ comprimento, $\mathrm{A}=$ altura e $\mathrm{C}=$ largura $)$ e dos seus furos, com o auxílio das seguintes equações:

$\mathrm{S}_{1}=2(\mathrm{AL})+2(\mathrm{CL})+2\left\{(\mathrm{AC})-\left[\left(12 \mathrm{CF}_{1} \mathrm{LF}_{1}\right)+\left(2 \mathrm{CF}_{2} \mathrm{LF}_{2}\right)+\left(4 \mathrm{CF}_{3} \mathrm{LF}_{3}\right)+\left(4 \pi \mathrm{r}^{2}\right)+\left(\mathrm{CF}_{4} \mathrm{LF}_{4}\right)\right]\right\}$

$\mathrm{S}_{2}=\left\{\left[12\left(2 \mathrm{CF}_{1} \mathrm{~L}+2 \mathrm{LF}_{1} \mathrm{~L}\right)\right]+\left[2\left(2 \mathrm{LF}_{2} \mathrm{~L}+2 \mathrm{CF}_{2} \mathrm{~L}\right)\right]+\left[4\left(2 \mathrm{CF}_{3} \mathrm{~L}+2 \mathrm{LF}_{3} \mathrm{~L}\right)\right]+[4(2 \pi \mathrm{rL})]+\left[2\left(\mathrm{CF}_{4} \mathrm{~L}\right)\right]+\left[2\left(\mathrm{LF}_{4} \mathrm{~L}\right)\right]\right\}$

\section{Modelagem Matemática e Estimação de Parâmetros}

Destarte, a partir dos dados experimentais das áreas superficiais externa e interna, e volume do bloco ao longo do processo, foram propostos diversos modelos matemáticos, a fim de determinar qual modelo matemático descreveria corretamente esses parâmetros geométricos do bloco cerâmico durante o processo de secagem. Assim, após várias tentativas, chegou-se a um modelo exponencial, como exibem as Equações 5 e 7, como sendo o mais apropriado para descrever as áreas superficiais externa e interna, e volume do bloco ao longo do processo. Dado o modelo, os ajustes para as variações dimensionais (área externa e interna) e volumétricas foram realizados utilizando o software Statistica ${ }^{\circledR}$ e o método numérico Quasi-Newton, com critério de convergência de 0,000099. 
$\mathrm{S}_{1}(\mathrm{t})=\mathrm{S}_{10}\left[\mathrm{a}_{1}+\mathrm{b}_{1} \times \operatorname{Exp}^{\left(-\mathrm{k}_{1}{ }^{\mathrm{n}} \mathrm{t}\right)}\right]$

$\mathrm{S}_{2}(\mathrm{t})=\mathrm{S}_{20}\left[\mathrm{a}_{2}+\mathrm{b}_{2} \times \operatorname{Exp}^{\left(-\mathrm{k}_{2}{ }^{\mathrm{z}} \mathrm{t}\right)}\right]$

$V(t)=V_{0}\left[a_{3}+b_{3} \times \operatorname{Exp}^{\left(-k s^{2} t\right)}\right]$

onde, $\mathrm{V}_{0}$ e $\mathrm{S}_{0}$ correspondem ao volume e às áreas (interna e/ou externa) iniciais, e as variáveis $\mathrm{a}_{1}, \mathrm{~b}_{1}, \mathrm{k}_{1}, \mathrm{a}_{2}, \mathrm{~b}_{2}, \mathrm{k}_{2}, \mathrm{a}_{3}, \mathrm{~b}_{3}$ e $\mathrm{k}_{3}$ são parâmetros estimados a partir do ajuste não-linear. Trata-se de uma pesquisa puramente teórica de caráter predominantemente quantitativo, que se baseia em trabalhos reportados na literatura (Silva, 2018; Pereira et al., 2018; Nascimento et al., 2020).

\section{Resultados e Discussão}

A Tabela 4 resume os valores das áreas superficiais interna e externa, e volume no início e no final da secagem, para diferentes condições experimentais.

Tabela 4. Dados dimensionais do bloco cerâmico após a secagem.

\begin{tabular}{c|c|c|c|c|c|c}
\hline \multicolumn{6}{c}{ Parâmetros geométricos do bloco cerâmico } \\
\hline \multirow{2}{*}{$\mathbf{T}\left({ }^{\circ} \mathbf{C}\right)$} & \multicolumn{3}{c|}{ Início da Secagem } & \multicolumn{3}{c}{ Final da secagem } \\
\cline { 2 - 7 } & $\mathbf{S}_{\mathbf{1 1 0}\left(\mathbf{m}^{2}\right)}$ & $\mathbf{S}_{\mathbf{2 0}}\left(\mathbf{m}^{\mathbf{2}}\right)$ & $\mathbf{V}_{\mathbf{0}}\left(\mathbf{m}^{\mathbf{2}}\right)$ & $\mathbf{S}_{\mathbf{1 f}}\left(\mathbf{m}^{\mathbf{2}}\right)$ & $\mathbf{S}_{\mathbf{2 f}}\left(\mathbf{m}^{\mathbf{3}}\right)$ & $\mathbf{V}_{\mathbf{f}}\left(\mathbf{m}^{\mathbf{3}}\right)$ \\
\hline 50 & 0,217272 & 0,521678 & 0,0039565 & 0,195438 & 0,489788 & 0,0032241 \\
\hline 60 & 0,212183 & 0,539122 & 0,0035383 & 0,193746 & 0,493774 & 0,0030994 \\
\hline 70 & 0,213621 & 0,534213 & 0,0036821 & 0,194911 & 0,501646 & 0,0031096 \\
\hline 80 & 0,216028 & 0,532609 & 0,0038429 & 0,196406 & 0,496006 & 0,0032523 \\
\hline 90 & 0,213822 & 0,535149 & 0,0037321 & 0,196619 & 0,497364 & 0,0032642 \\
\hline 100 & 0,216586 & 0,522916 & 0,0038693 & 0,20005 & 0,496608 & 0,0033858 \\
\hline
\end{tabular}

Fonte: Silva (2018).

As Tabelas de 5 a 7 apresentam os coeficientes de determinação obtidos após ajuste aos dados experimentais das áreas superficiais interna e externa e volume do bloco cerâmico para cada condição experimental. É sabido que o coeficiente de determinação é um dos métodos de avaliar a qualidade do ajuste do modelo matemático proposto; quanto mais próximo de 1,0 for esse coeficiente, melhor é a capacidade do modelo de explicar os dados obtidos experimentalmente.

Ao analisar os coeficientes de determinação encontrados para as variações das áreas externa e interna e do volume do bloco, observa-se que, para todas as condições experimentais estudadas, o seu valor foi superior à 0.9 , implicando que o modelo matemático escolhido ajustou-se adequadamente aos dados experimentais obtidos por Silva (2018).

Ao realizar o ajuste ao modelo matemático aos dados experimentais é possível, através dos gráficos, exibir a relação entre o modelo matemático predito e os dados experimentais obtidos por Silva (2018). Sabe -se que no início da etapa de secagem, as partículas que compõem a massa cerâmica encontram-se cercadas pela água adicionada durante a etapa de conformação e, uma vez que na secagem a peça é submetida a temperaturas mais elevadas, ocorre a evaporação dessa água promovendo uma aproximação entre as partículas que compõem a massa. Este fenômeno de aproximação, que ocorre de forma simultânea ao transporte de umidade, é chamado de retração, sendo o responsável por alterar a cinética de secagem do sólido e suas respectivas dimensões. 
Tabela 5. Parâmetros estatísticos da Equação 5 obtidos após ajuste aos dados experimentais da área superficial externa do bloco cerâmico.

\begin{tabular}{c|c|c|c|c|c}
\hline \multirow{2}{*}{$\mathbf{T}\left({ }^{\circ} \mathbf{C}\right)$} & \multicolumn{3}{|c|}{ Parâmetros } & \multirow{2}{*}{$\mathbf{R}$} & $\begin{array}{c}\text { Proporção da } \\
\text { Variância }\end{array}$ \\
\cline { 2 - 5 } & $\mathbf{a}$ & $\mathbf{b}_{1}$ & $\mathbf{k}_{1}$ & & $97,636 \%$ \\
\hline 50 & 0,901906 & 0,094942 & $-0,118153$ & 0,98811 & $98,081 \%$ \\
\hline 60 & 0,916317 & 0,089238 & $-0,107296$ & 0,99036 & $98,512 \%$ \\
\hline 70 & 0,913417 & 0,090522 & $-0,136887$ & 0,99253 & $99,115 \%$ \\
\hline 90 & 0,906832 & 0,095390 & $-0,142611$ & 0,99557 & $98,688 \%$ \\
\hline 100 & 0,918261 & 0,081259 & $-0,145465$ & 0,99342 & $99,032 \%$ \\
\hline
\end{tabular}

Fonte: Dados da Pesquisa.

Tabela 6. Parâmetros estatísticos da Equação 6 obtidos após ajuste aos dados experimentais da área superficial interna do bloco cerâmico.

\begin{tabular}{c|c|c|c|c|c}
\hline \multirow{2}{*}{ T $\left({ }^{\circ} \mathbf{C}\right)$} & \multicolumn{3}{|c|}{ Parâmetros } & \multirow{2}{*}{ R } & $\begin{array}{c}\text { Proporção da } \\
\text { Variância }\end{array}$ \\
\cline { 2 - 5 } & $\mathbf{a} 2$ & $\mathbf{b} 2$ & $\mathbf{k} 2$ & 0,97195 & $94,468 \%$ \\
\hline 50 & 0,934331 & 0,078248 & $-0,099675$ & 0,98306 & $96,641 \%$ \\
\hline 60 & 0,916679 & 0,092013 & $-0,117138$ & 0,96829 & $93,759 \%$ \\
\hline 70 & 0,936533 & 0,076191 & $-0,092472$ & 0,97994 & $96,027 \%$ \\
\hline 90 & 0,933251 & 0,085057 & $-0,108381$ & 0,98181 & $96,394 \%$ \\
\hline 100 & 0,930446 & 0,077706 & $-0,116544$ & 0,95470 & $91,145 \%$ \\
\hline
\end{tabular}

Fonte: Dados da Pesquisa.

Tabela 7. Parâmetros estatísticos da Equação 7 obtidos após ajuste aos dados experimentais do volume do bloco cerâmico.

\begin{tabular}{c|c|c|c|c|c}
\hline \multirow{2}{*}{$\mathbf{T}\left({ }^{\circ} \mathbf{C}\right)$} & \multicolumn{3}{|c|}{ Parâmetros } & \multirow{2}{*}{$\mathbf{R}$} & $\begin{array}{c}\text { Proporção da } \\
\text { Variância }\end{array}$ \\
\cline { 2 - 5 } & 0,827963 & 0,156506 & $-0,153099$ & 0,94327 & $88,975 \%$ \\
\hline 50 & 0,883788 & 0,118260 & $-0,103415$ & 0,95307 & $90,835 \%$ \\
\hline 60 & 0,845889 & 0,168594 & $-0,193381$ & 0,98252 & $96,536 \%$ \\
\hline 70 & 0,836882 & 0,156642 & $-0,185467$ & 0,98638 & $97,295 \%$ \\
\hline 90 & 0,868853 & 0,127073 & $-0,195847$ & 0,97831 & $95,709 \%$ \\
\hline 100 & 0,877361 & 0,125252 & $-0,202705$ & 0,98602 & $97,224 \%$ \\
\hline
\end{tabular}

Fonte: Dados da Pesquisa.

As Figuras 3 a 5 exibem o comportamento transiente das áreas superficiais externa e interna, e volume do bloco cerâmico durante o processo de secagem, tanto experimental quanto predito pelo modelo proposto. 
Figura 3. Variação predita (_) e experimental $\left({ }^{\circ \circ}\right)$ da área superficial externa do bloco cerâmico em função do tempo de secagem para diferentes temperaturas.

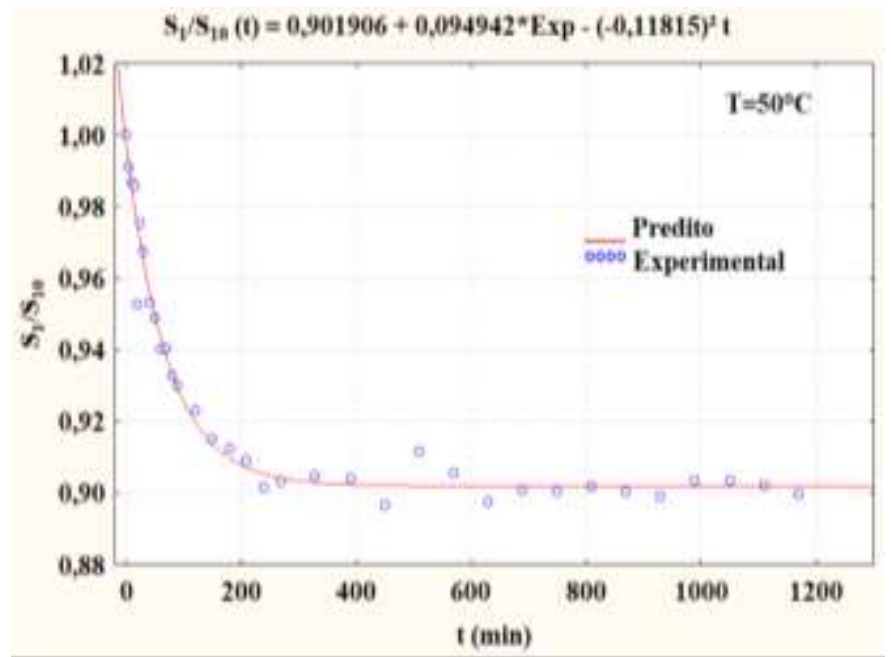

(a) $\quad \mathrm{T}=50^{\circ} \mathrm{C}$

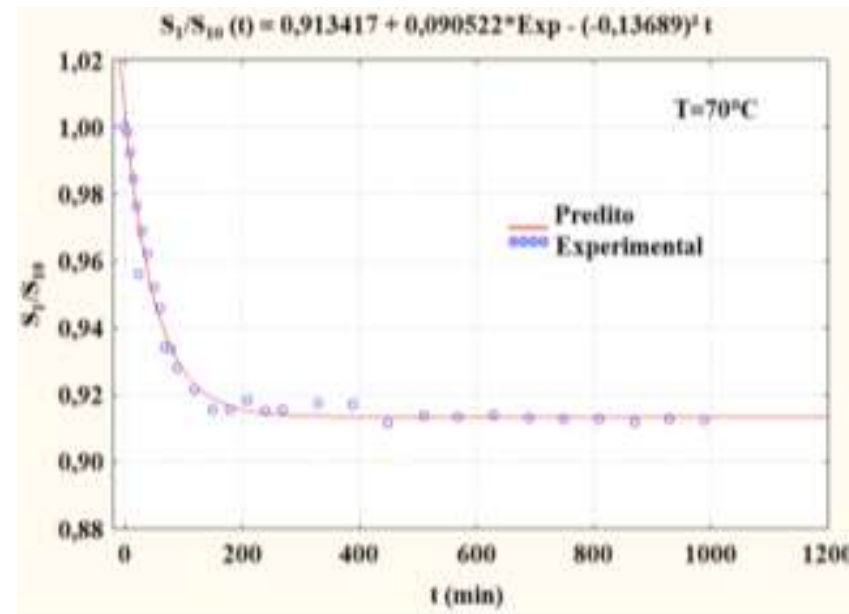

(c) $\quad \mathrm{T}=70^{\circ} \mathrm{C}$

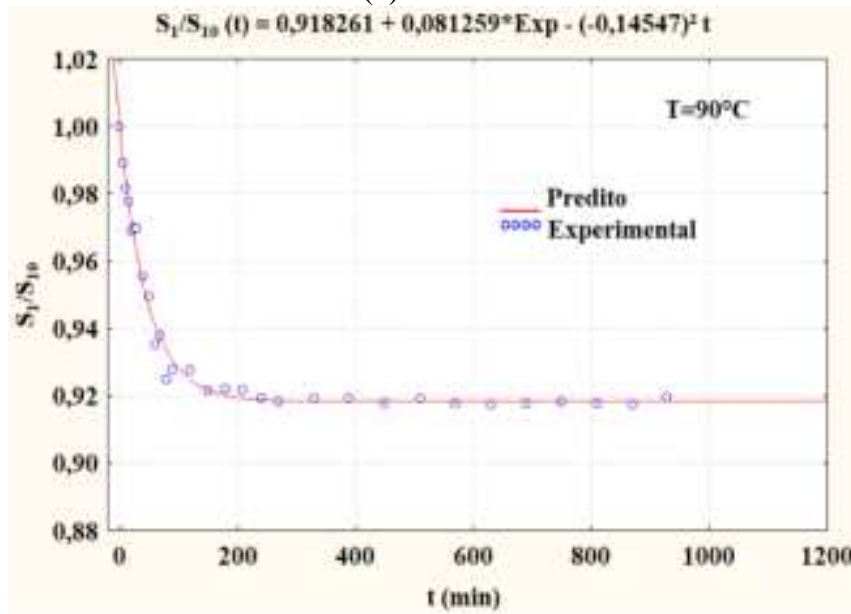

(e) $\quad \mathrm{T}=90^{\circ} \mathrm{C}$

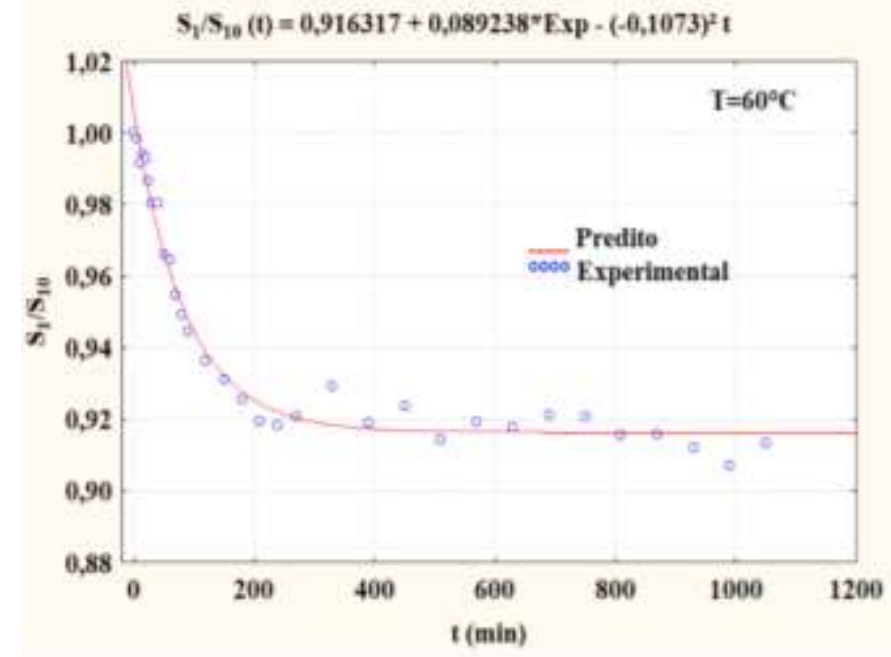

(b) $\mathrm{T}=60^{\circ} \mathrm{C}$

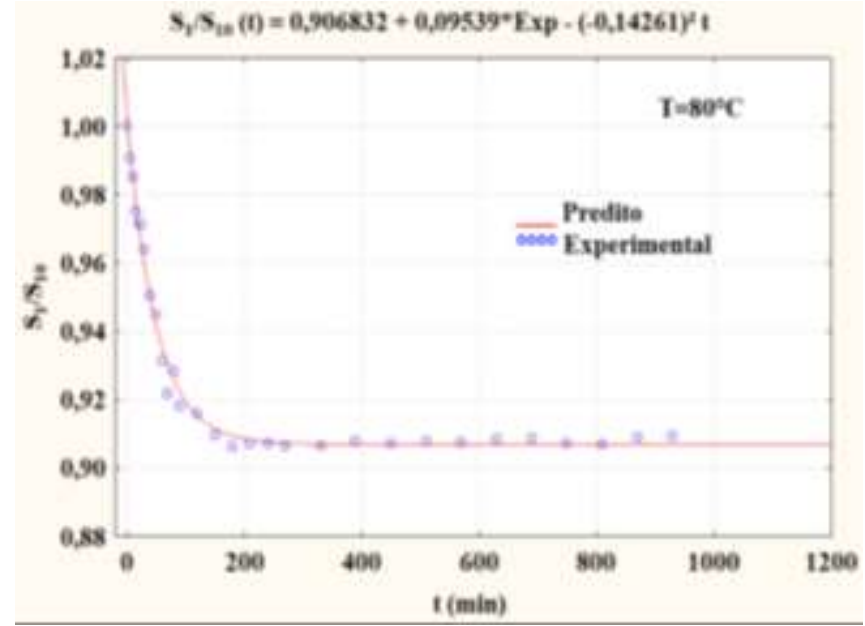

(d) $\mathrm{T}=80^{\circ} \mathrm{C}$

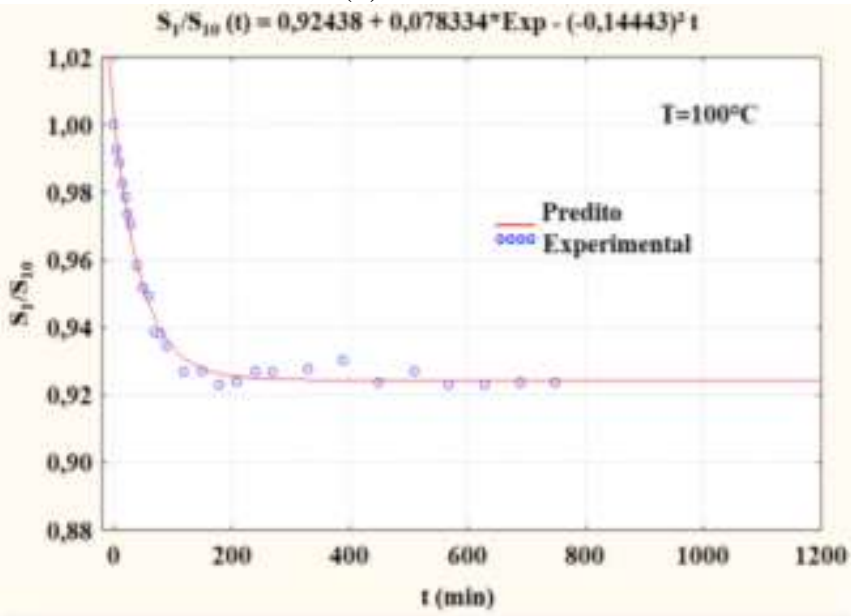

(f) $\mathrm{T}=100^{\circ} \mathrm{C}$

Fonte: Dados da Pesquisa. 
Figura 4. Variação predita (__ e experimental $\left({ }^{\circ \circ}\right)$ da área superficial interna do bloco cerâmico em função do tempo de secagem em diferentes temperaturas.

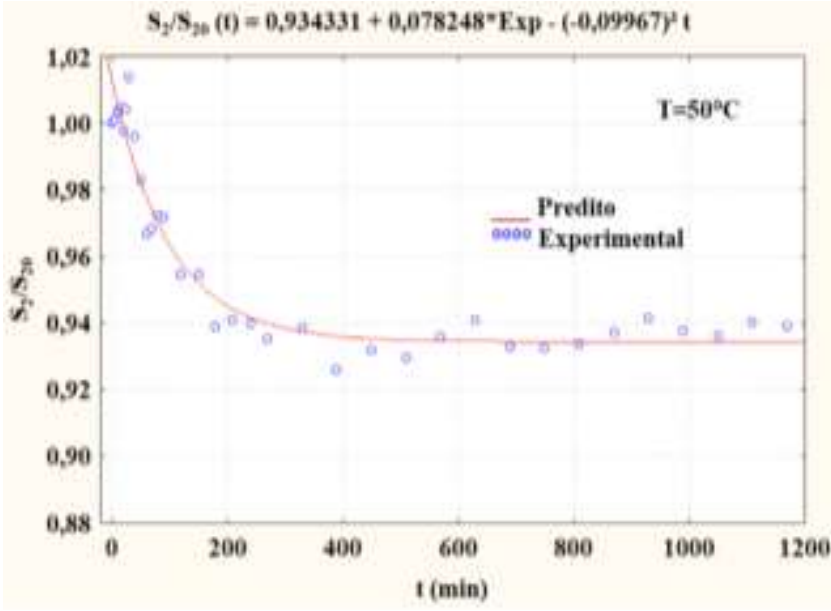

(a) $\quad \mathrm{T}=50^{\circ} \mathrm{C}$

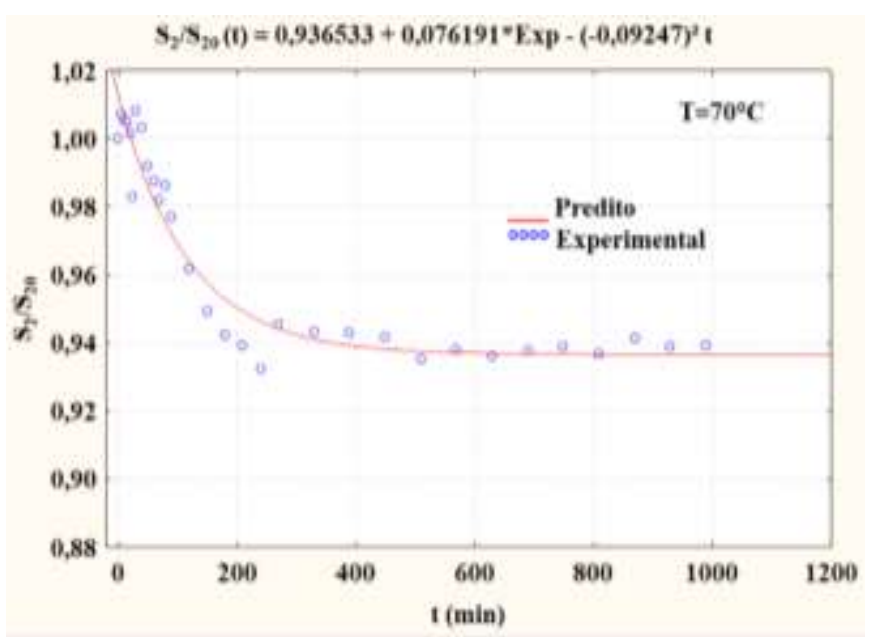

(c) $\quad \mathrm{T}=70^{\circ} \mathrm{C}$

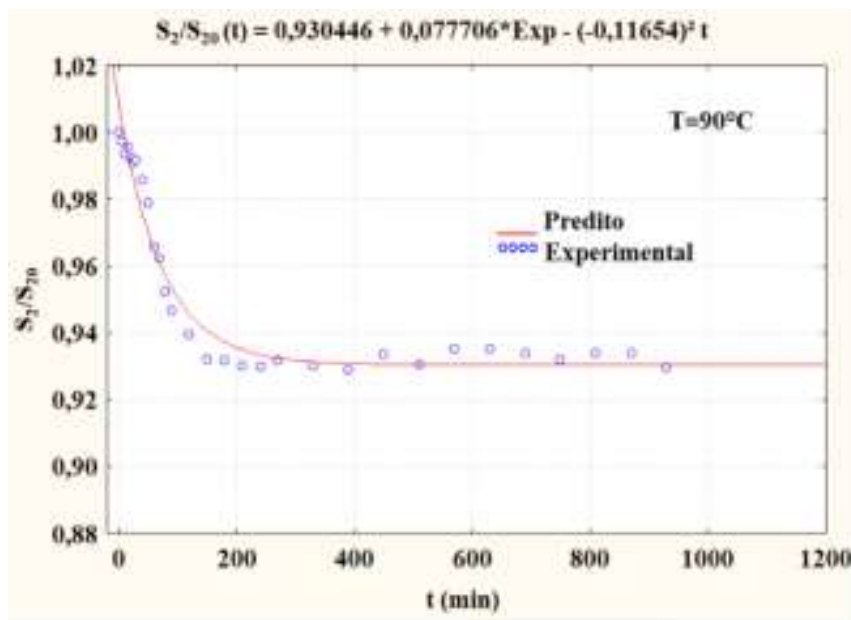

(e) $\quad \mathrm{T}=90^{\circ} \mathrm{C}$

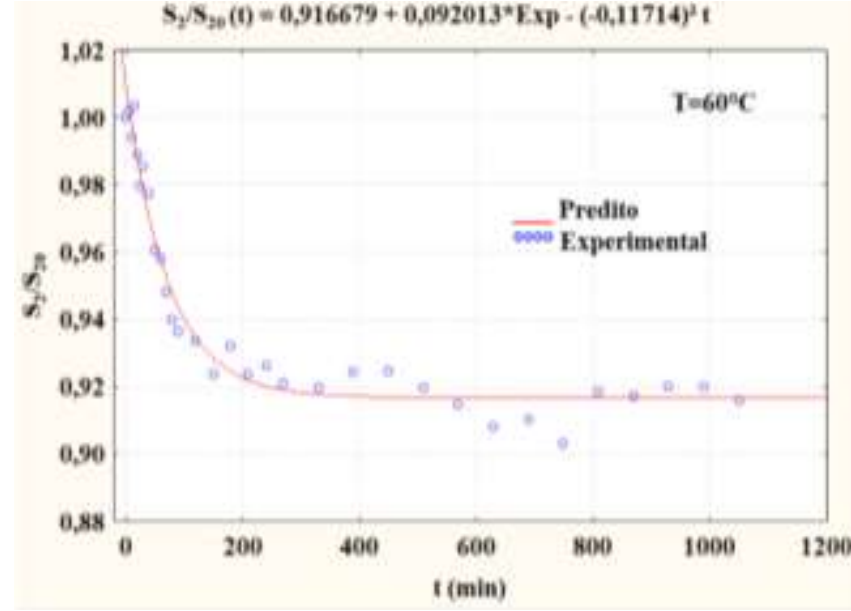

(b) $\mathrm{T}=60^{\circ} \mathrm{C}$

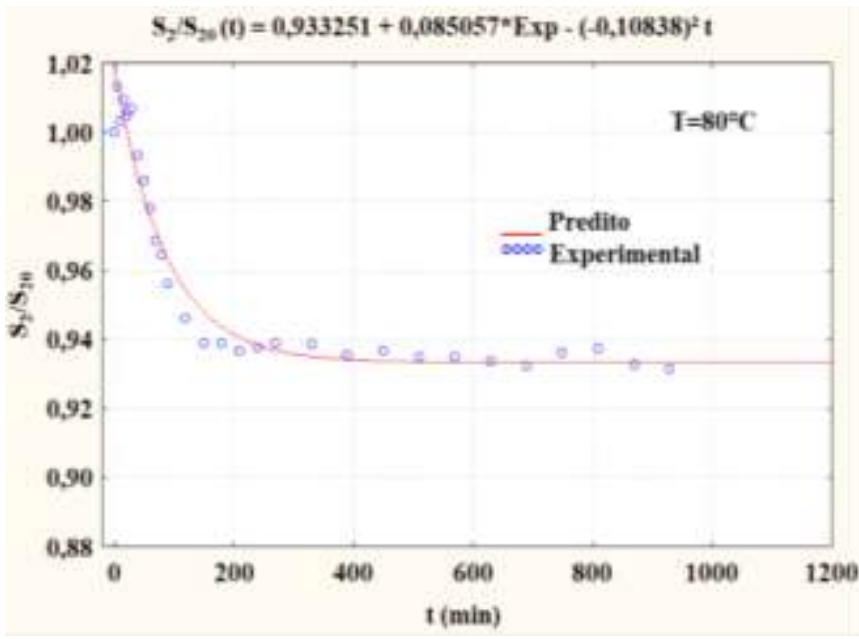

(d) $\mathrm{T}=80^{\circ} \mathrm{C}$

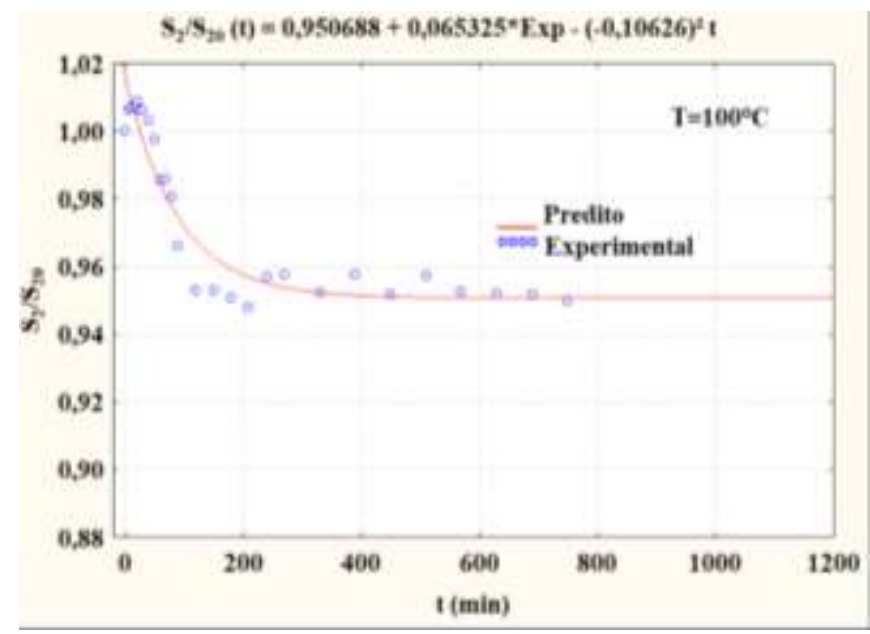

(f) $\mathrm{T}=100^{\circ} \mathrm{C}$

Fonte: Dados da Pesquisa. 
Figura 5. Variação predita (_) e experimental $\left({ }^{\circ 00}\right)$ do volume do bloco cerâmico em função do tempo de secagem em distintas temperaturas.

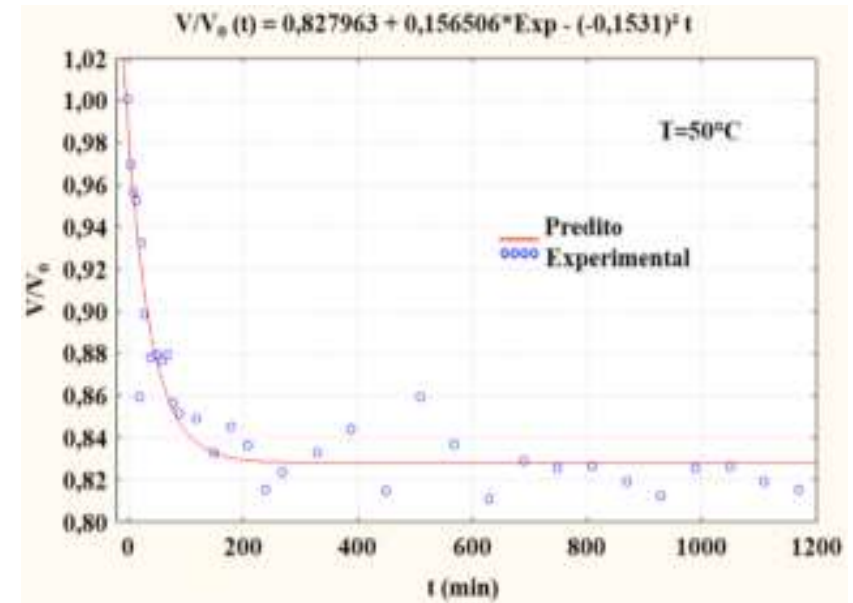

(a) $\mathrm{T}=50^{\circ} \mathrm{C}$

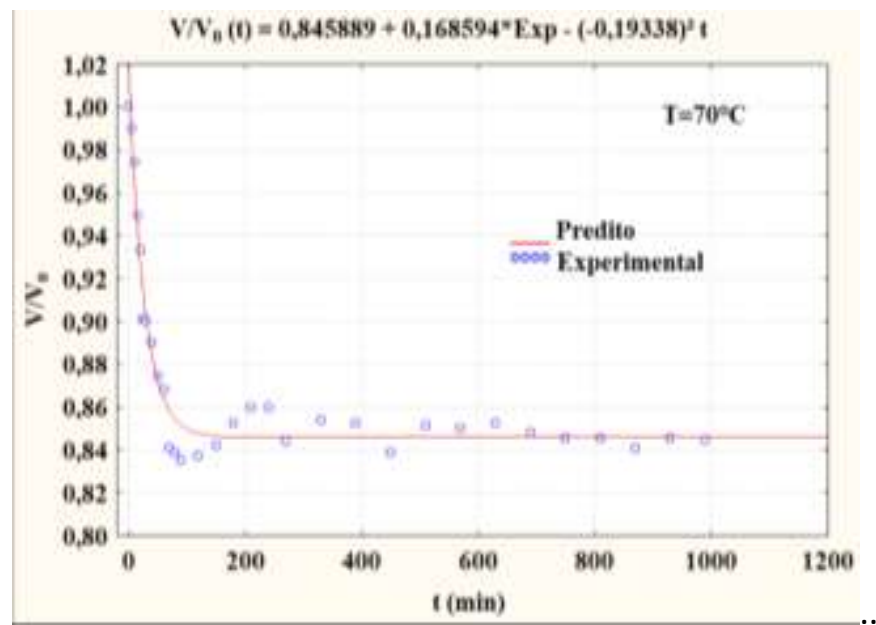

(c) $\quad \mathrm{T}=70^{\circ} \mathrm{C}$

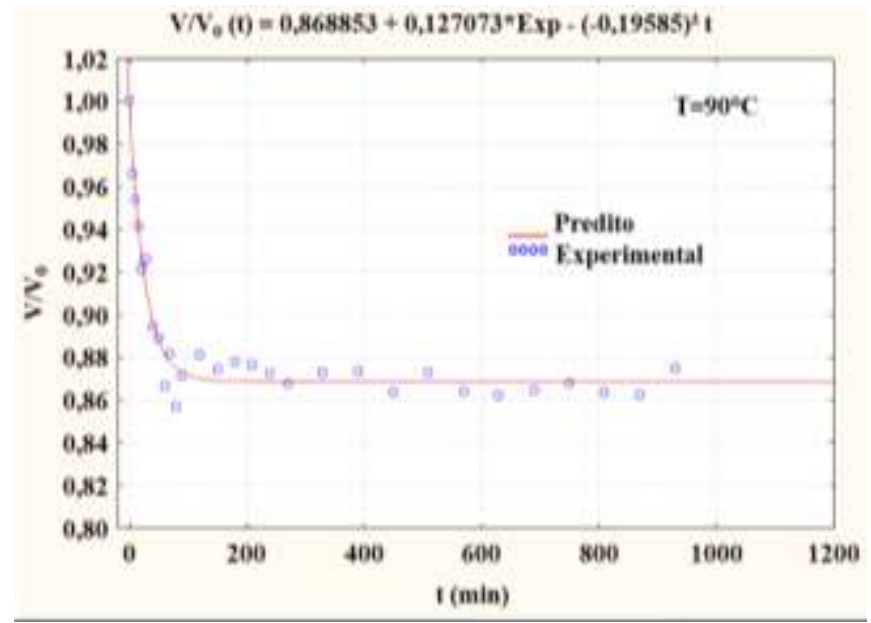

(e) $\quad \mathrm{T}=90^{\circ} \mathrm{C}$

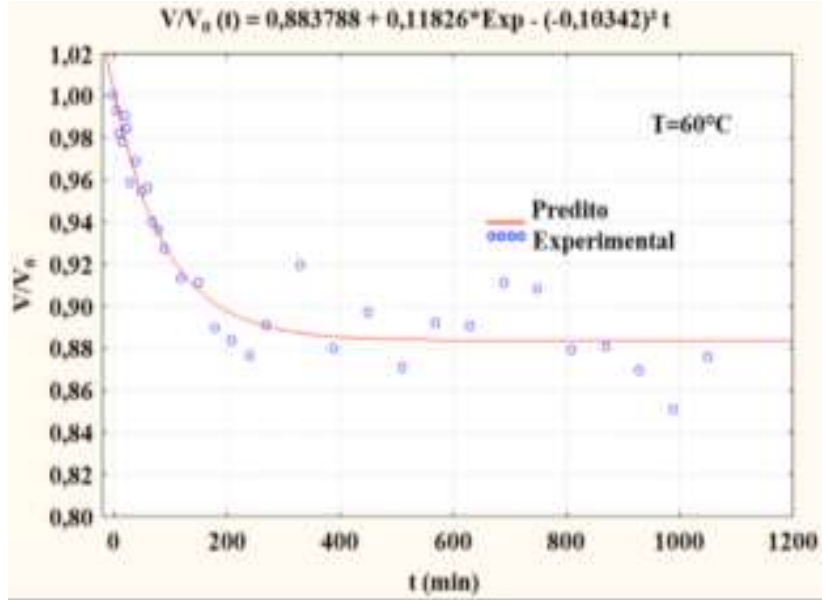

(b) $\mathrm{T}=60^{\circ} \mathrm{C}$

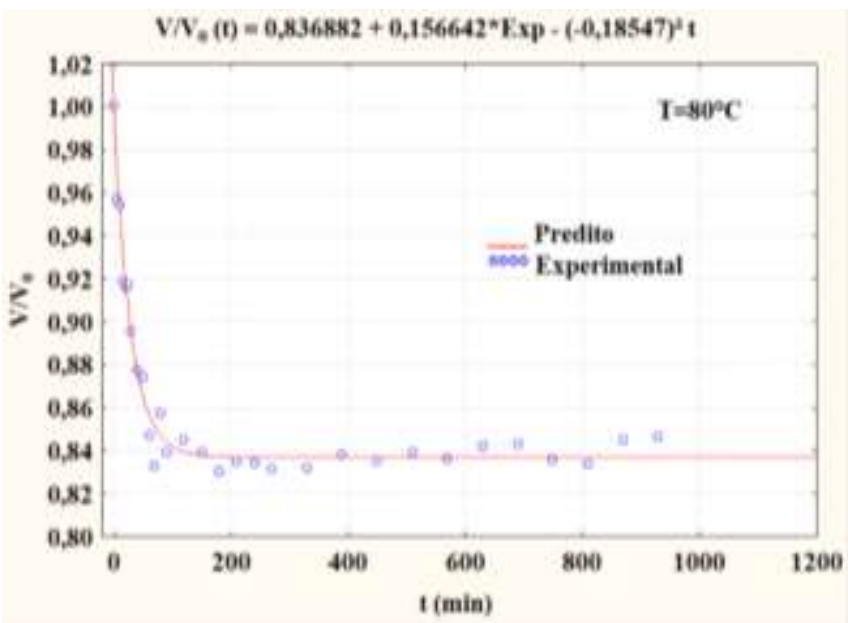

(d) $\mathrm{T}=80^{\circ} \mathrm{C}$

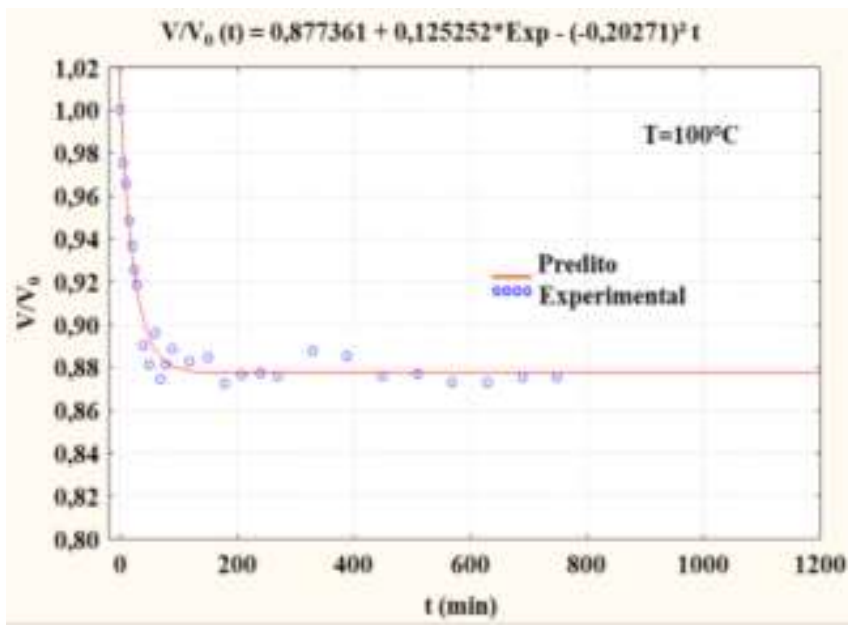

(f) $\mathrm{T}=100^{\circ} \mathrm{C}$

Fonte: Dados da Pesquisa.

É reportado na literatura que nos primeiros minutos da etapa de secagem há uma grande remoção da umidade existente na peça; esta remoção é a responsável pelas dimensões dos sólidos variarem inicialmente em uma velocidade mais 
elevada, tendendo a manterem-se constantes após um longo período. É possível observar esse comportamento ao analisar-se as Figuras 3 a 5. Tanto as áreas superficiais externa e interna, quanto o volume do bloco cerâmico, até os 200 minutos de processo, decresceram rapidamente, sofrendo uma variação média de 8,72\%, 6,6\% e 14,48\%, respectivamente.

Segundo Almeida (2009), no início da secagem a variação dimensional de um sólido é proporcional ao decréscimo do volume de umidade existente no mesmo. Após o decréscimo abrupto das dimensões do bloco nos primeiros minutos de processo, a retração continuou, porém, em uma velocidade mais lenta comparada ao estágio inicial da secagem. Ao se analisar as Figuras 3 a 5, nota-se que, para todas as temperaturas, após os 200 minutos de processo, ainda houve variações dimensionais, entretanto, essas variações ocorreram em uma taxa mais lenta, assumindo muitas vezes um comportamento quase constante para tempos longos. É possível notar, para determinadas temperaturas de secagem, um caráter oscilatório destes parâmetros para tempos longos de processo. Este evento deu-se essencialmente pelo fato de que, durante a secagem, ocorrem dois fenômenos simultaneamente: o encolhimento volumétrico que acontece enquanto a umidade é retirada do sólido, e a expansão volumétrica que se sucede devido ao aquecimento da peça. Presume-se também a ocorrência de erros durante a coleta dos dados experimentais, uma vez que para obter os dados em sua pesquisa, Silva (2018) retirava o bloco cerâmico da estufa para realizar as medições. Destarte, é possível constatar que para temperaturas mais elevadas, onde há um aquecimento maior do bloco, as variações apresentaram um comportamento mais oscilatório e isto se deu justamente pelos fenômenos de encolhimento e expansão que ocorreram simultaneamente.

Sabe-se que a geometria do sólido influencia na sua cinética de secagem, onde em sólidos vazados, o ar de secagem consegue uma melhor circulação em seu interior. Ao comparar os dados dimensionais expostos na Tabela 4 com os gráficos mostrados nas Figuras 3 a 5, é possível notar que a área interna do bloco é maior que a sua área externa.

Ademais, ao analisar a Tabela 4 e as Figuras 3 a 5 é possível verificar que, para as temperaturas de $50^{\circ} \mathrm{C}$ e $100^{\circ} \mathrm{C}, \mathrm{o}$ volume do bloco obteve uma redução de $18,51 \%$ e $12,5 \%$, respectivamente. Já para as áreas superficiais externa e interna, as reduções foram de $10,05 \%$ e $6,11 \%$ para a temperatura de $50^{\circ} \mathrm{C}$, e de $7,66 \%$ e $5,03 \%$ para a temperatura de $100^{\circ} \mathrm{C}$. Comparando esses dados, é notório que, proporcionalmente, as áreas sofreram uma redução menor do que aquela do volume; isto é um fator importante, pois implica que o bloco não sofreu grandes deformações, mantendo assim, sua geometria original.

Tendo em vista a importância do tópico abordado neste trabalho, os autores sugerem que novas pesquisas qualitativas e quantitativas relacionadas à secagem de materiais cerâmicos sejam conduzidas, com vistas a ampliar os conhecimentos sobre este importante processo e seus efeitos na qualidade e custo final do produto. Isto inclui experimentos com outros produtos cerâmicos com dimensões industriais, e o desenvolvimento e aplicação de modelos avançados/melhorados relacionados a transferência de calor e massa, e variações dimensionais durante a secagem destes materiais. Finalmente, com este artigo, os autores esperam poder contribuir com um melhor entendimento do processo de secagem de materiais cerâmicos, de forma a fornecer informações adicionais para que engenheiros, especialistas, acadêmicos e industriais, possam tomar decisões conscientes, que possibilitem as empresas do setor ceramista, a se tornarem mais competitivas nos mercados nacional e internacional.

\section{Conclusão}

A presente pesquisa expôs uma investigação teórica referente ao processo de secagem de blocos cerâmicos estruturais; onde, através de modelos matemáticos baseados no método de análise concentrada, as variações das áreas superficiais interna e externa, e volume ocorridas no produto foram analisadas durante o processo. Destarte, a partir dos resultados obtidos, pode-se concluir:

a) O modelo matemático exponencial proposto para predizer as variações das áreas superficiais externa e interna, e volume do bloco cerâmico durante a secagem foi satisfatório, provado pelo valor do coeficiente de determinação encontrado 
através do ajuste dos dados experimentais ao modelo proposto, que foi superior à 0.9 , em todas as condições experimentais estudadas;

b) Para os primeiros 200 minutos de processo, o bloco apresentou uma abrupta redução em suas dimensões, corroborando com o fato de que no início da secagem, a variação das áreas superficiais interna e externa, e volumétrica são proporcionais ao decréscimo de umidade no bloco, ocorrendo em velocidades mais elevadas, para tempos longos;

c) A temperatura de $50^{\circ} \mathrm{C}$ foi a que apresentou a maior variação volumétrica e da área externa, sendo seus valores de $18,51 \%$ e 10,05\%, respectivamente. Já para a área interna, a temperatura que apresentou maior variação foi a de $60^{\circ} \mathrm{C}$, cuja redução foi de $8,4 \%$;

d) Ao se comparar as variações transientes dos parâmetros geométricos estudados, é possível notar que, proporcionalmente, o volume apresentou uma maior variação quando comparado às áreas superficiais interna e externa do bloco cerâmico, implicando que o bloco cerâmico manteve a sua geometria inicial, ou seja, não apresentou grandes deformações, p que é muito bom para a sua qualidade pós secagem.

\section{Agradecimentos}

Os autores agradecem a CAPES, ao CNPq, e a FINEP pelo apoio financeiro, e aos pesquisadores referenciados no texto que, com suas pesquisas, contribuíram para o melhoramento do trabalho.

\section{Referências}

Alexandre, C. A. B. (2017). Caracterização dos blocos cerâmicos estruturais produzidos no Estado do Ceará. [Dissertação de Mestrado, Universidade Federal do Ceará].

Almeida, G.S. (2009). Simulação e experimentação da secagem de cerâmica vermelha em sistemas térmicos industriais. [Tese de Doutorado, Universidade Federal de Campina Grande].

Araújo, M. V., Correia, B. R. B., Brandão, V. A. A., Oliveira, I. R., Santos, R. S., Neto, G. L. O., \& Lima, A. G. B. (2020). Convective Drying of Ceramic Bricks by CFD: Transport Phenomena and Process Parameters Analysis. Energies, 13(2073). doi:10.3390/en13082073

Barros, M. P. (2021). Um modleo simplificado para análise de desempenho de um refrigerador evaporativo de cerâmica. Research and Teaching in Exact and Natural Sciences, 5.

Bellingieri, J. C. (2005). As origens da indústria cerâmica em São Paulo. Cerâmica Industrial, 10(3), 19-23.

Braga, W. A., Santos, M. W. L. C., \& Sales, J. C. (2016). Qualidade na indústria de cerâmica vermelha: medidas e alternativas para o controle dimensional. Cerâmica Industrial, 20.

Brito, M. K. T. (2016). Estudo teórico da transferência de calor e massa na secagem de tijolos cerâmicos com forma paralelepipédica [Dissertação de Mestrado, Universidade Federal de Campina Grande].

Faustino, D. B. L. (2016). Secagem de tijolos cerâmicos no formato de paralelepipedo: teorias de secagem. [Trabalho de Conclusão de Curso, Universidade Estadual da Paraíba].

Ibrahim, M. H. D., W. R. W.; Talib, M. Z. M. (1997). Drying characteristics of oil palm kernels. Drying Technology, 15(3), $1103-1117$.

Lima, E. S., Lima, W. M. P. B., Silva, S. K. B. M., Magalhães, H. L. F., Nascimento, L. P. C., Gomez, R. S., \& Lima, A. G. B. (2020). Secagem de tijolos cerâmicos industriais e estimativa de parâmetros do processo: uma abordagem concentrada avançada. Research, Society and Development, 9(12).

Lima, W. M. P. B. (2017). Transferência de calor e massa em sólidos porosos com geometria complexa via análise concentrada: modelagem e simulação. [Dissertação de Mestrado, Universidade Federal de Campina Grande].

Lima, W. M. P. B., Silva, E. H., Lima, E. S., Gomez, R. S., Magalhães, H. L. F., Silva, S. K. B. M., Porto, T. R. N., \& Lima, A. G. B. (2020). Secagem de materiais cerâmicos argilosos com forma complexa: uma análise teórica usando o método de capacitância global. Research, Society and Development, 9 (11).

Martinez, P. H. (2017). Influência da geometria de blocos cerâmicos no comportamento de vigas paredes de alvenaria estrutural. [Dissertação de Mestrado, Universidade Estadual Paulista].

Motta, J. F. M., Zanardo, A., \& Cabral Júnior, M. (2001). As matérias-primas cerâmicas. Parte I: o perfil das principais indústrias cerâmicas e seus produtos. Cerâmica Industrial, 6(2), 28-39.

Nascimento, J. J. S., Lima, A. G. B., Santana, E. W. F., Belo, F. A., Neves, G. A., Santana, L. N. L., \& Batista, V. R. (2005). Experimental drying of ceramic bricks including shrinkage. Paper presented at the 18th International Congress of Mechanical Engineering, Ouro Preto - MG. 
Research, Society and Development, v. 10, n. 6, e33310615680, 2021

(CC BY 4.0) | ISSN 2525-3409 | DOI: http://dx.doi.org/10.33448/rsd-v10i6.15680

Nascimento, L. P. C., Silva, S. K. B. M., Lima, E. S., Magalhães, H. L. F., Lima, W. M. P. B., Gomez, R. S., \& Lima, A. G. B. (2020). Secagem de tijolos cerâmicos argilosos industriais: uma investigação teórica usando modelos concentrados. Research, Society and Development, 9(11).

Nascimento, J. J. S., Luna, C. B. B., Costa, R. F., Barbieri, L. F. P., \& Bezerra, E. O. T. (2019). Evaluation of red clay and ball clay drying using transient threedimensional mathematical modeling: volumetric shrinkage and moisture content. Materials Research Express, 6.

Pereira A. S., Shitsuka, D. M., Parreira, F. J., \& Shitsuka, R. (2018). Metodologia da pesquisa científica. Editora UAB/NTE/UFSM, Santa Maria/RS.

Recuperado de https://repositorio.ufsm.br/bitstream/handle/1/15824/Lic_Computacao_Metodologia Pesquisa-Cientifica.pdf?sequence=1

Prado, U. S., \& Bressiani, J. C. (2013). Panorama da indústria cerãmica brasileira na última década. Cerâmica Industrial, 18(1), 7-11.

Santos, R. S. Estudo do processo de secagem de blocos cerâmicos estruturais: modelagem e simulação. (2019). [Tese de Doutorado, Universidade Federal de Campina Grande].

Silva, A. M. V. (2018). Secagem de blocos cerâmicos industriais: modelagem, simulação e experimentação [Tese de Doutorado, Universidade Federal de Campina Grande].

Zaccaron, A., Nandi, V. S., \& Bernardin, A. M. (2020). Fast drying for the manufacturing of clay ceramics using natural clays. Journal of Building Engineering. 